\title{
Design of the Low Noise Amplifier Circuit in Band L for Improve the Gain and Circuit Stability
}

\author{
Arash Omidi ${ }^{\text {a*}}$, Rohalah Karami ${ }^{a}$, Parisa Sadat Emadi ${ }^{a}$, Hamed Moradi ${ }^{b}$ \\ ${ }^{a}$ Department of Engineering, Isfahan University of Technology, Isfahan, Iran \\ ${ }^{b}$ Research Company APM, Kermanshah, Iran
}

\begin{abstract}
In this paper, focuses on the design of Low Noise Amplifier circuitry in the frequency band L. This circuit is designed using the $0.18 \mathrm{~nm}$ CMOS transistor technology, which consists of two transistor Stage. The purpose of this research is to improve the cost of: Increase Gain - Increase circuit linearization - Create an integrative matching network for system stability. The application of this circuit can be used in wireless and GPS systems. The CMOS LNA exhibits a gain greater than $23 \mathrm{~dB}$ from 1.1 to $2.0 \mathrm{GHz}$, and a noise figure of 2.7 to $3.3 \mathrm{~dB}$ from 1.2 to $2.4 \mathrm{GHz}$. At $1.575 \mathrm{GHz}$, the $1-\mathrm{dB}$ compression point $(\mathrm{P} 1 \mathrm{~dB})$ is $1.73 \mathrm{dBm}$, with an input third-order intercept point (IIP3) of $-3.98 \mathrm{dBm}$ This circuit is designed using ADS software.
\end{abstract}

\section{Keywords:}

Gain;

Noise Figure;

LNA;

Linearization;

L Band.

Article History:

Received: 20 September 2017

Accepted: 8 December 2017

\section{1- Introduction}

Built-in Global Positioning System (GPS) capability is increasingly becoming a standard feature for cellular handset and other low-cost embedded applications. The requirements for these systems provide a strong motivation for developing highly integrated and low-cost GPS receivers. Low-noise amplifiers (LNAs) in GPS receivers are often the most challenging block to implement, given the difficulty of simultaneously achieving sufficient gain, low noise figure, and low power consumption. Typically, GPS receivers operate in the L-band frequency range $(1575.42 \mathrm{MHz}(\mathrm{L} 1)$, $1227.60 \mathrm{MHz}$ (L2), $1381.05 \mathrm{MHz}$ (L3) and $1176.45 \mathrm{MHz}$ (L5)). Designing a monolithic LNA at L-band poses significant challenges due to the large size of the passive components, making it difficult to implement the LNA with its requisite matching networks on-die. Complementary Metal-Oxide-Semiconductor (CMOS) [1] are attractive for analog, mixed-signal and RF applications because they exhibit very low noise figure and very high power gain, at modest power dissipation levels, which can be leveraged to improve the sensitivity of receiver front-ends. CMOS technology utilizes band gap engineering to improve transistor performance, and at present peak cutoff frequency (fT) and peak maximum oscillation frequency (fmax) greater than $300 \mathrm{GHz}$ have been achieved at modest lithographic feature size $(0.18 \mathrm{~nm})$, while maintaining compatibility with the traditional CMOS processes In this paper, we present a high gain, L-band CMOS LNA with fully-integrated on-chip matching networks. At $1.575 \mathrm{GHz}$, the LNA achieves a gain of 26 $\mathrm{dB}$, a NF of $3.2 \mathrm{~dB}$, while dissipating $17.89 \mathrm{~mW}$ of dc power.

Communication systems have been improving a lot in the last decades [1]. An important factor determining their improvement is on RF front end circuits [4, 6, 8, 9]. RF front-end components with high linearity and flat gain performance as well as high efficiency and low thermal dissipation loss are highly necessary [2, 3, 5, 7]. In case of satellite telecommunication, signal transmission travelling thousands of miles from the ground station-to-satellite and satellite-to-receiving fixed and mobile stations demands RF front-end transistors meeting stringent requirements. Specifications, including the low noise amplifier of receiving section. The low noise amplifier of the front-end should have sufficient sensitivity to receive very low signal amplitude as result through long distance propagation from satellite

\footnotetext{
* CONTACT: Arash_eng2020@yahoo.com
}

DOI: http://dx.doi.org/10.28991/ijse-01122

(C) This is an open access article under the CC-BY license (https://creativecommons.org/licenses/by/4.0/). 
at the orbital altitude to the terminal at the ground. As receiving section of the front end is sensing very low magnitude signal transmitted from satellite transponder, the Low Noise Amplifier (LNA) transistor plays the most important role in receiver front end circuit. The transistor used in this paper's LNA design is BFP720ESD, a Silicon Germanium Carbon (CMOS:C) NPN Hetero junction, a wideband RF Transistor [10]. This CMOS shows very low noise figure and low power consumption meeting ideal condition for an LNA implementation. The CMOS LNA has been designed meticulously. Proposed design in this paper shows high gain $(35.56 \mathrm{~dB})$ with very low noise figure $(0.628 \mathrm{~dB})$ using this transistor. Modulation analysis has also been performed in this paper to gain EVM (error vector magnitude) and ACLR (adjacent channel rejection ratio) parameters with WCDMA input signal of 3.84 MHz bandwidth [11].

\section{2- LNA Design}

The LNA was implemented as a single-ended cascade amplifier [3] with a feedback network. The first stage is a common-emitter (CE) configuration and the second stage is a common-base (CB) configuration. The cascode transistor $\mathrm{Q}_{2}$ prevents the Miller effect from degrading the power gain and also improves the reverse isolation, and improves stability of the LNA. The feedback topology [5] for the LNA uses a shunt-shunt configuration with both the resistance $\mathrm{R}_{\mathrm{fb}}$ and the capacitance $\mathrm{C}_{\mathrm{fb}}$ connected in series. Figure 1 shows the small-signal equivalent circuit for the transistors $\mathrm{Q}_{1}$ and $\mathrm{Q}_{2}$ in a cascade configuration without feedback. Assuming that the gain at $\mathrm{Q}_{1}$ is greater $\mathrm{Q}_{2}$, the equivalent noise input current, $\mathrm{I}_{\mathrm{ni}}$ for a shunt-shunt feedback amplifier [7] is given as:

$$
\begin{aligned}
& I_{n i}=\left[\frac{4 k T \Delta f}{R s+f_{b}}\left(1+\frac{r x}{R_{s}+R_{f b}}\right)+2 q I_{B} \Delta f\left(1+\frac{r x}{R_{s}+R_{b}}\right)^{2}+2 q I_{c} \Delta f\left[\frac{1}{\beta}+\frac{1}{R_{s}+R_{b}}\left(\frac{r_{x}}{\beta}+\frac{V_{T}}{I_{c}}\right)\right]^{2}\right]^{\frac{1}{2}} \\
& G M=g m \\
& A_{v}=g m R_{s}
\end{aligned}
$$

For the shunt-shunt feedback amplifier, the closed-loop gain $\mathrm{A}_{\text {close }}$ of the amplifier is given by:

$$
\begin{aligned}
& A_{\text {close }}=\frac{A+\Delta A}{1+(A+\Delta A) B_{f}} \approx \frac{A}{1+A B_{f}}+\frac{\Delta A}{1+A B_{f}} \\
& A_{\text {close }} \approx \frac{1}{B_{f}} \approx R_{f b}
\end{aligned}
$$

The amount of SNR (in, out) is as follows:

$$
\begin{aligned}
& S N R_{\text {in }}=\int_{-\infty}^{\infty} \frac{|P(\omega)|^{2}}{S V_{g}(\omega)} d \omega_{0} \\
& S N R_{\text {out }}=\int_{-\infty}^{\infty} \frac{|P(\omega)|^{2}}{S V_{g}(\omega)+S V_{\text {in }}(\omega)} d \omega_{0}
\end{aligned}
$$

The closed-loop input impedance of the feedback amplifier is given by:

$$
Z_{i f} \approx \frac{R_{i}\left(R_{f b}\right)}{R_{f b}+A}
$$

Where A is the open-loop gain. The closed-loop output impedance of the feedback amplifier is given by:

$$
Z_{o f} \approx \frac{R_{o}\left(R_{f b}\right)}{R_{f b}+A}
$$

The minimum effect of a linear network in the order of the system is expressed in Noise figure. The $R_{f b}$ value is larger than the $\mathrm{R}_{\mathrm{s}}$ with the input impedance. Figure 1 shows the small-signal equivalent circuit for the transistors $\mathrm{Q}_{1}$ and $\mathrm{Q}_{2}$ in a cascade configuration without feedback. In Figure 2, the schematic of the L-band LNA is shown. Tables 1 shows the device sizes for the LNA. 


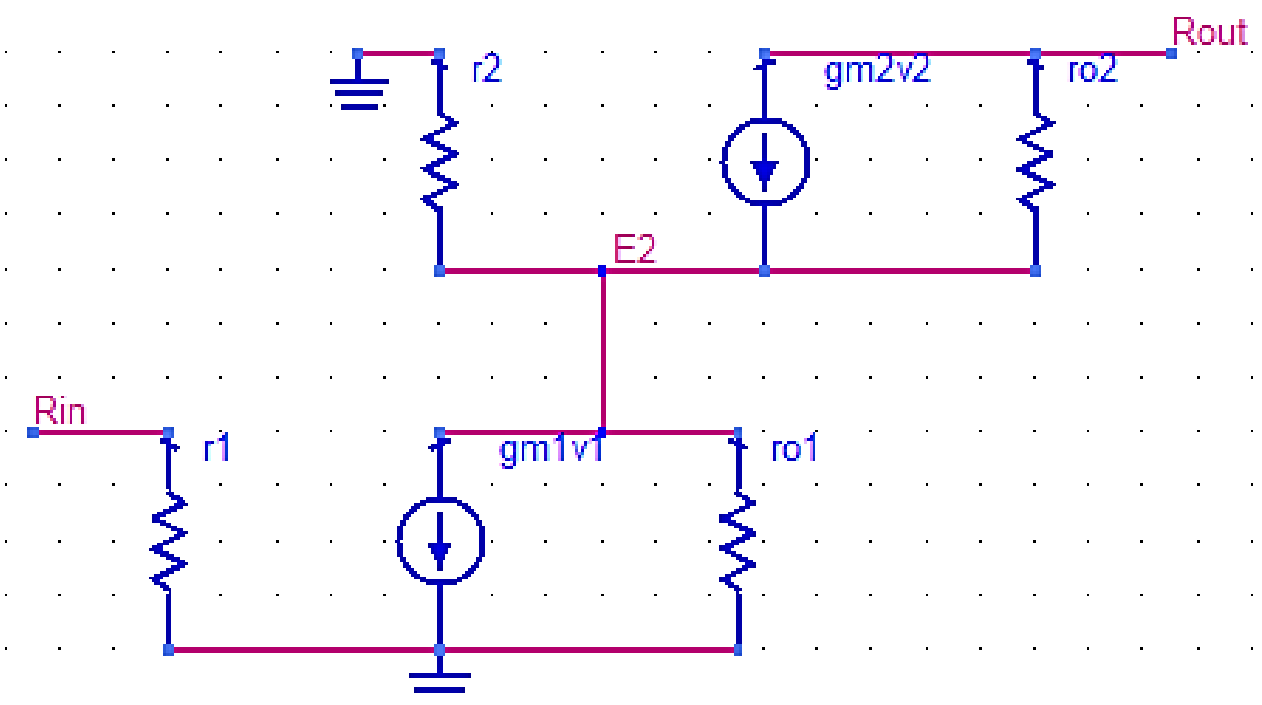

Figure 1. Small-signal.

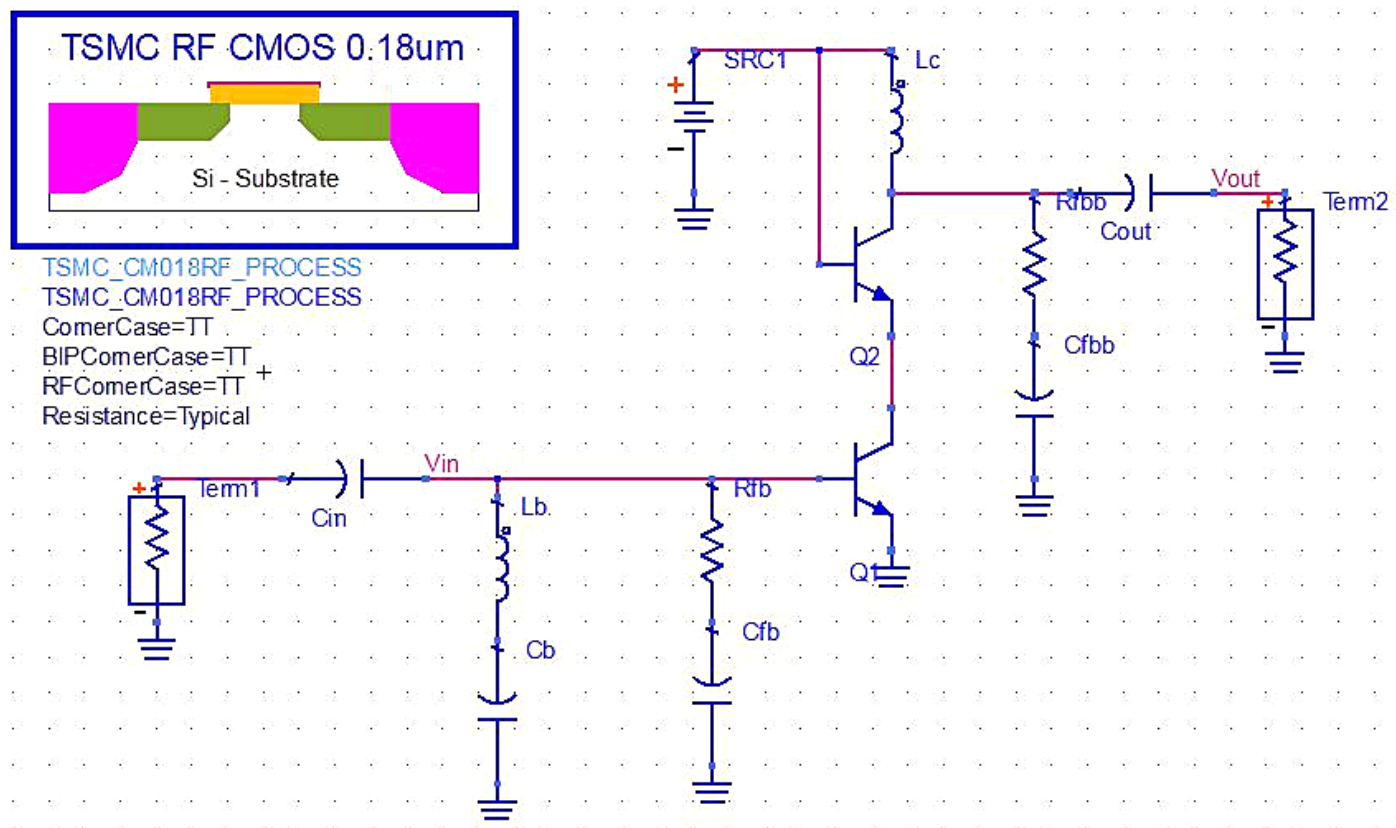

Figure 2. Schematic of the L-band LNA.

Table 1. Device sizes for the L-band CMOS LNA.

\begin{tabular}{cccccccccc}
\hline Parameter & Q2 & Q1 & Cout & Cfb & Rfb & Lc & Cb & Lb & Cin \\
\hline Device Sizes & 0.18 & 0.18 & $976.8 \mathrm{fF}$ & $11.5 \mathrm{~K} \Omega$ & $4.8 \mathrm{~K} \Omega$ & $13.5 \mathrm{nH}$ & $10 \mathrm{pF}$ & $7.3 \mathrm{nH}$ & $2 \mathrm{pF}$ \\
\hline
\end{tabular}

\section{3- Simulation of LNA}

The LNA was designed to operate off of a supply voltage as low as Vcc=1.5 V and Ic=11.9 mA, yielding a total power dissipation of $17.89 \mathrm{~mW}$. The LNA was measured on-wafer using ground-signal-ground (GSG) coplanar microwave probes, with probe-level calibration used to account for cable losses. The LNA achieves a peak gain of 26 $\mathrm{dB}$ at $1.575 \mathrm{GHz}$, and from 1.1-4.0 GHz, it maintains a gain above $22 \mathrm{~dB}$. The reverse isolation of the LNA is more than $35 \mathrm{~dB}$ from 1 to $4 \mathrm{GHz}$ indicating good stability. The LNA exhibits a good $50 \Omega$ match and Figure 6 shows that the measured and simulated input return loss (S11) and the output return loss (S22) are less than -10 dB from 1.1-1.9 GHz. 


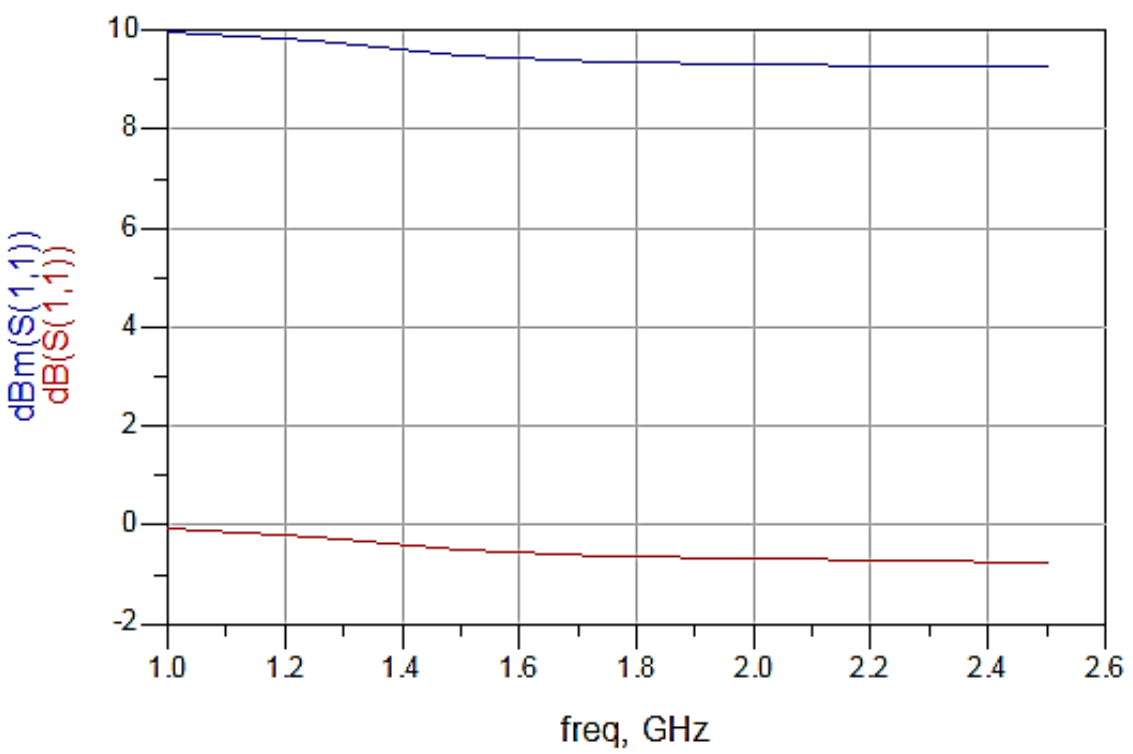

Figure 3. Parameter chart $S_{11}$.

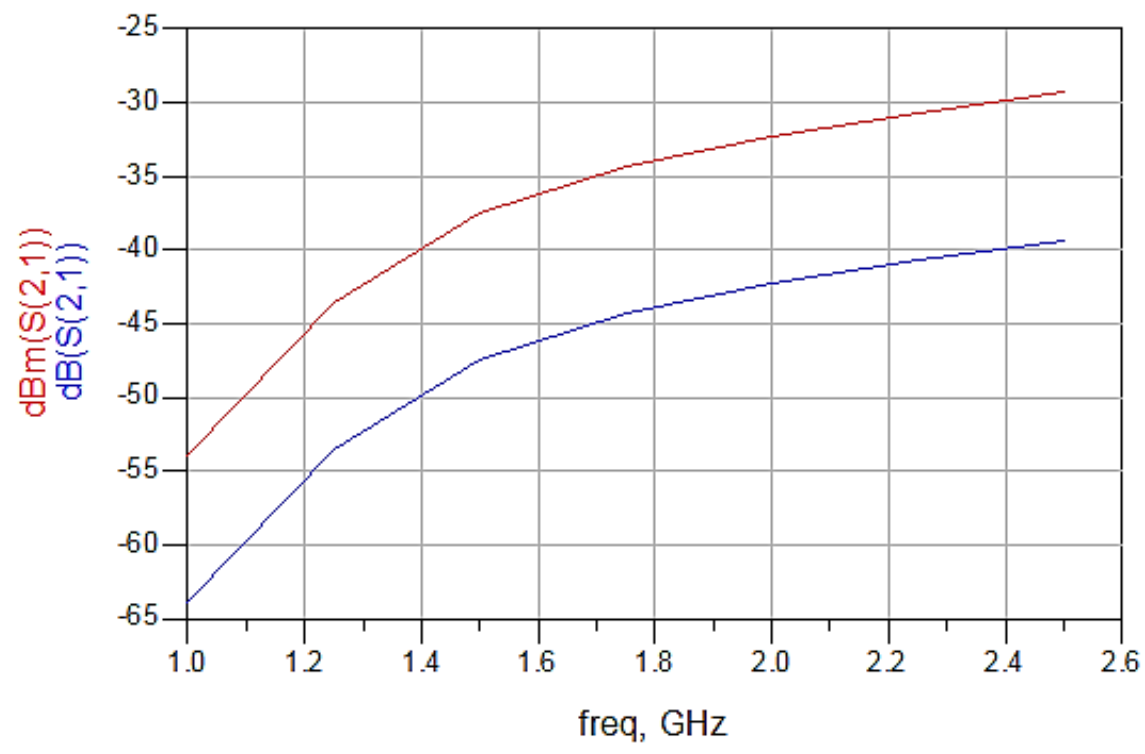

Figure 4. Parameter chart $S_{12}$.

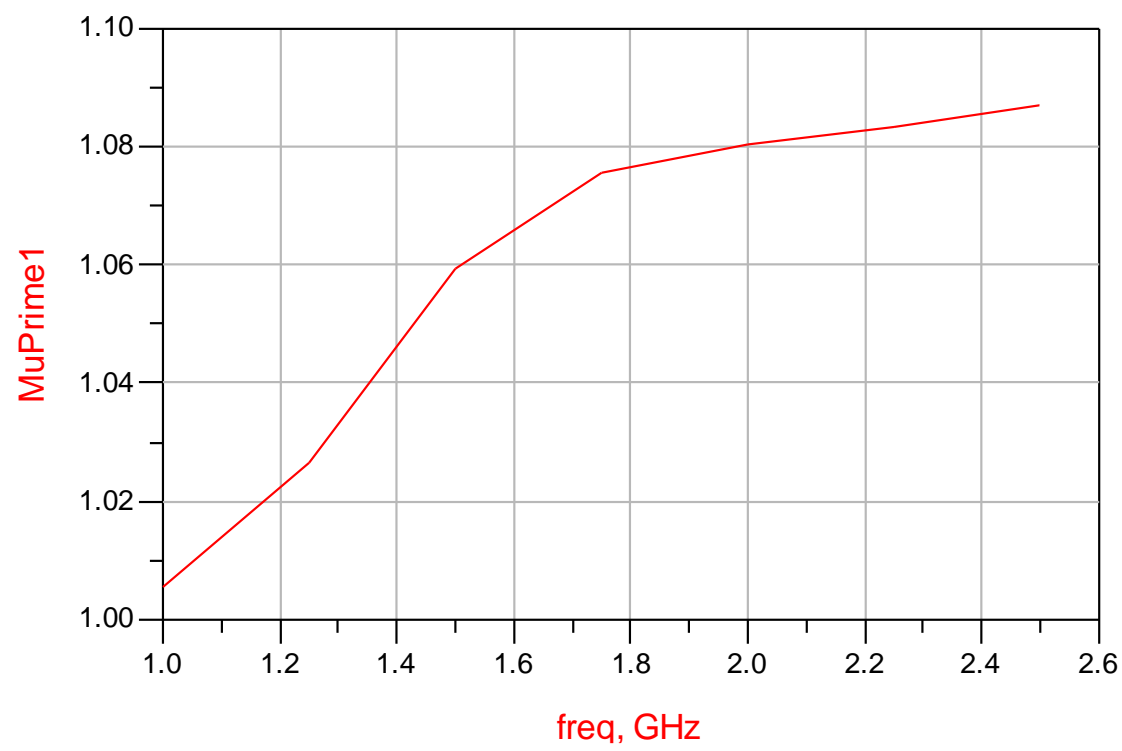

Figure 5. The MU parameter chart of the initial values of S. 


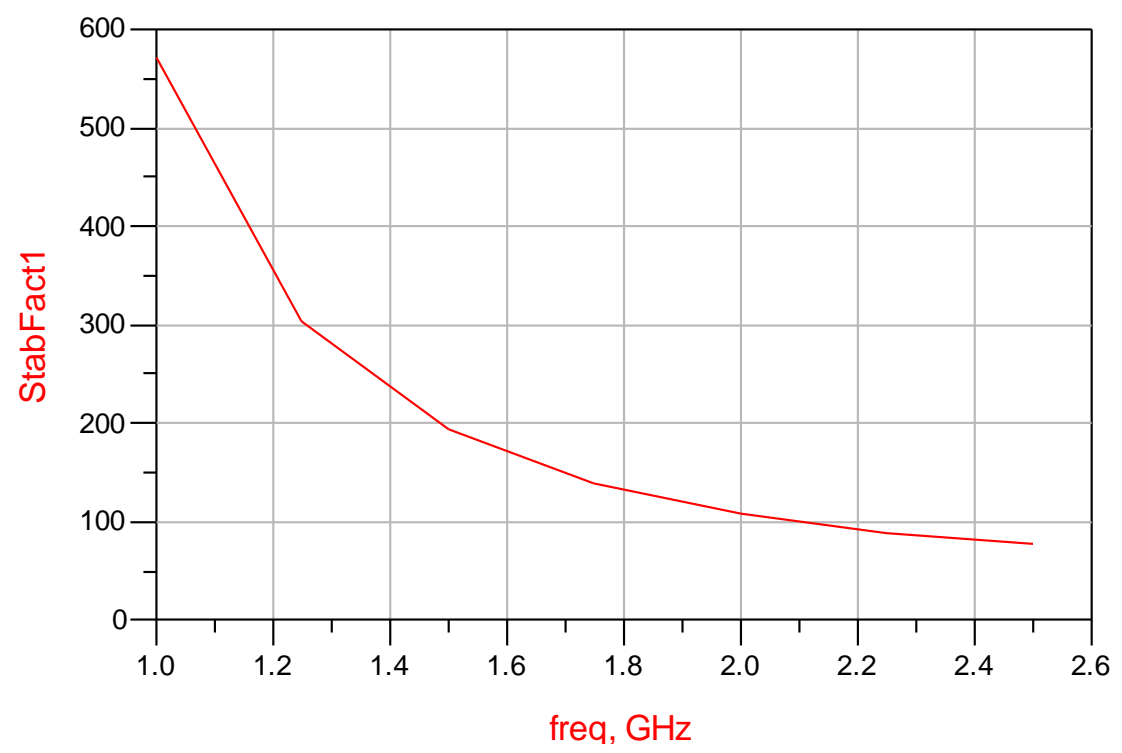

Figure 6. Chart stability.

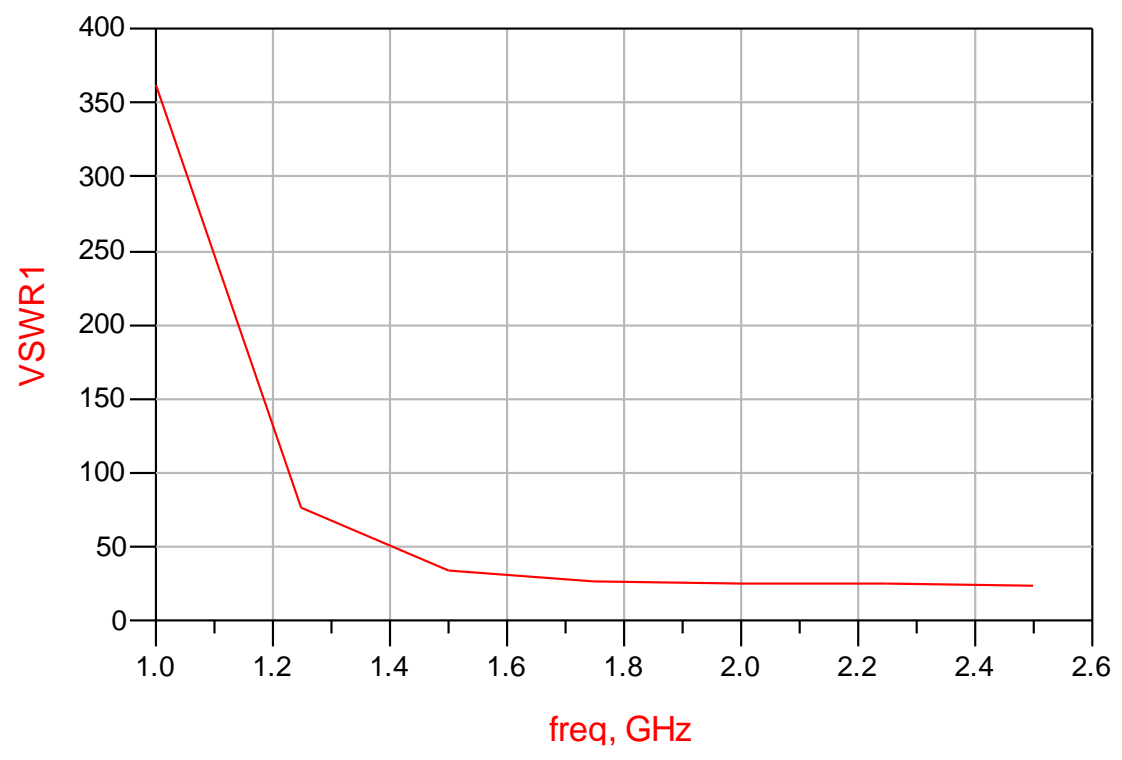

Figure 7. Voltage VSWR chart in parameter $S$.

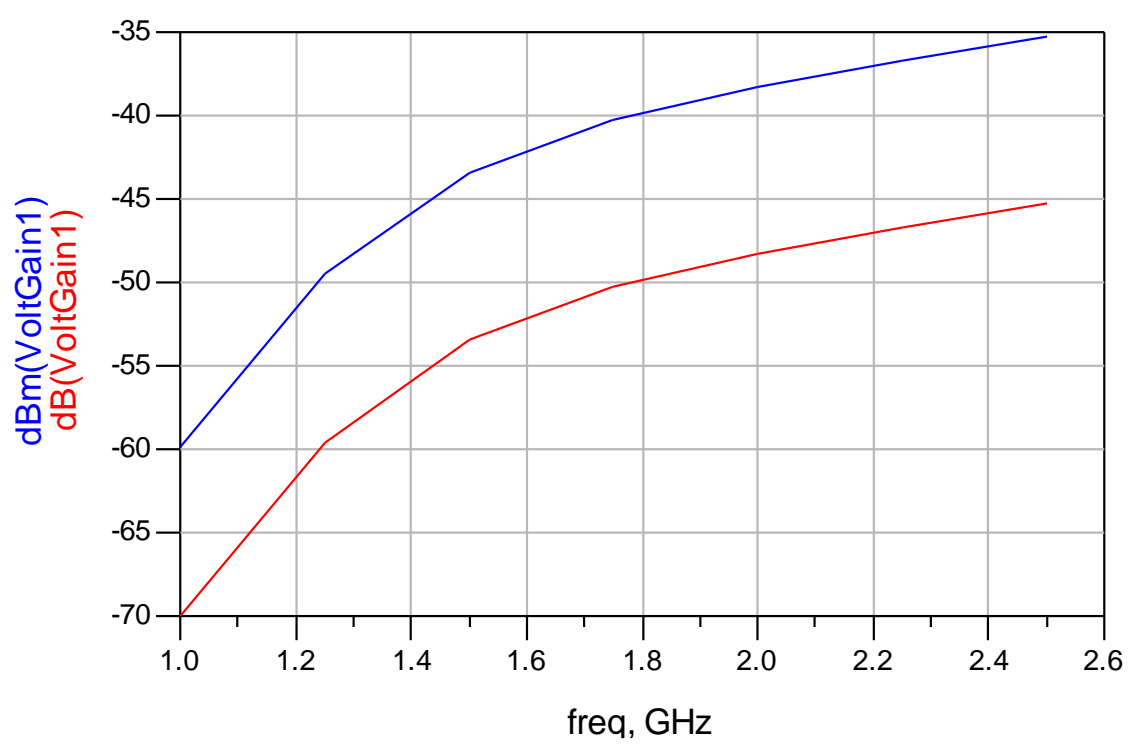

Figure 8. Voltage chart. 


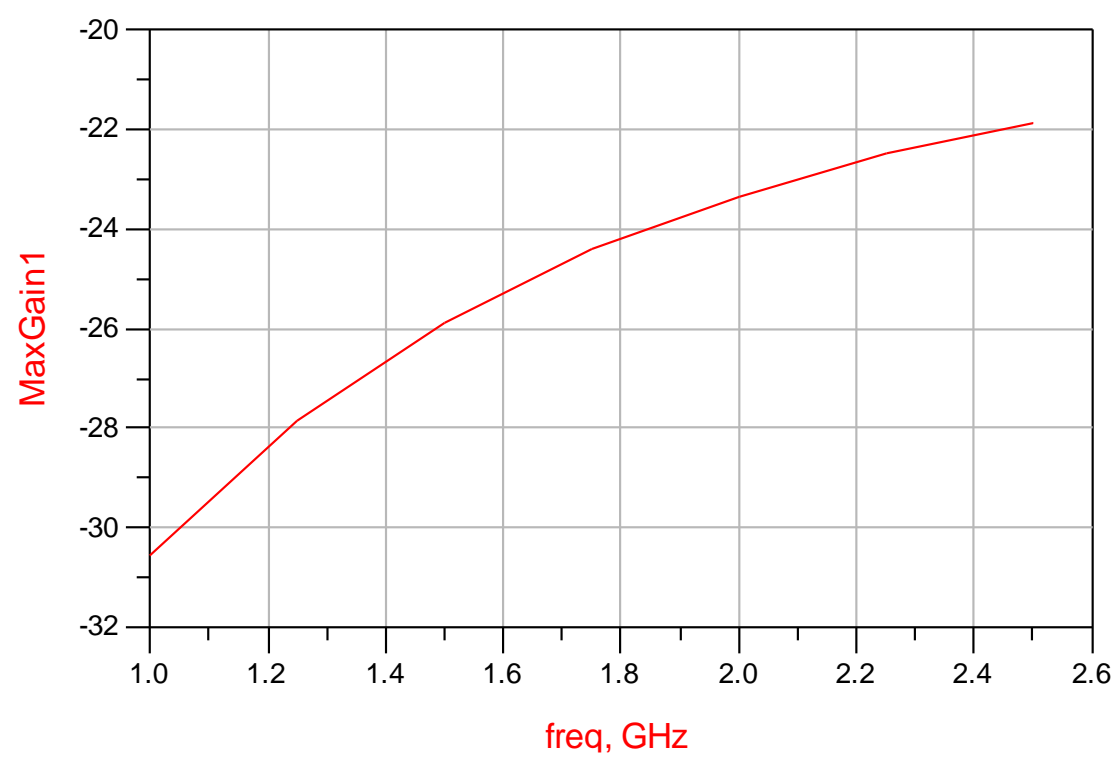

Figure 9. Maximum Circuit chart.

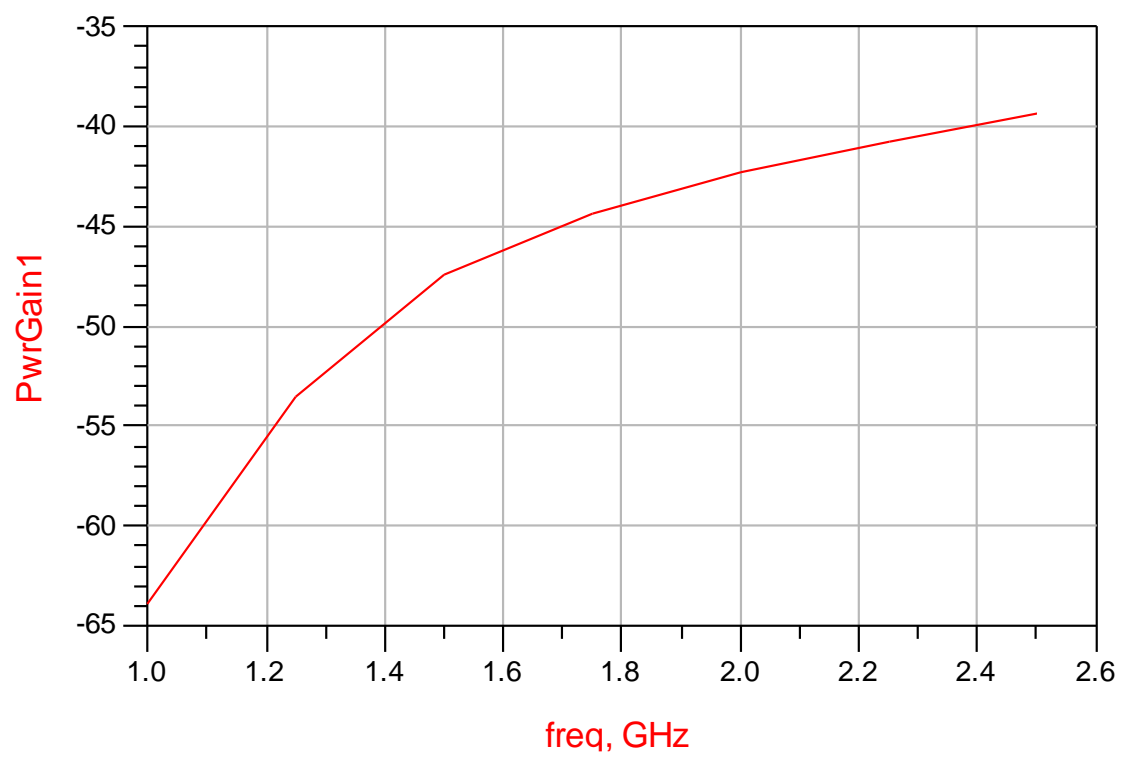

Figure 10. Circuit output circuit diagram.

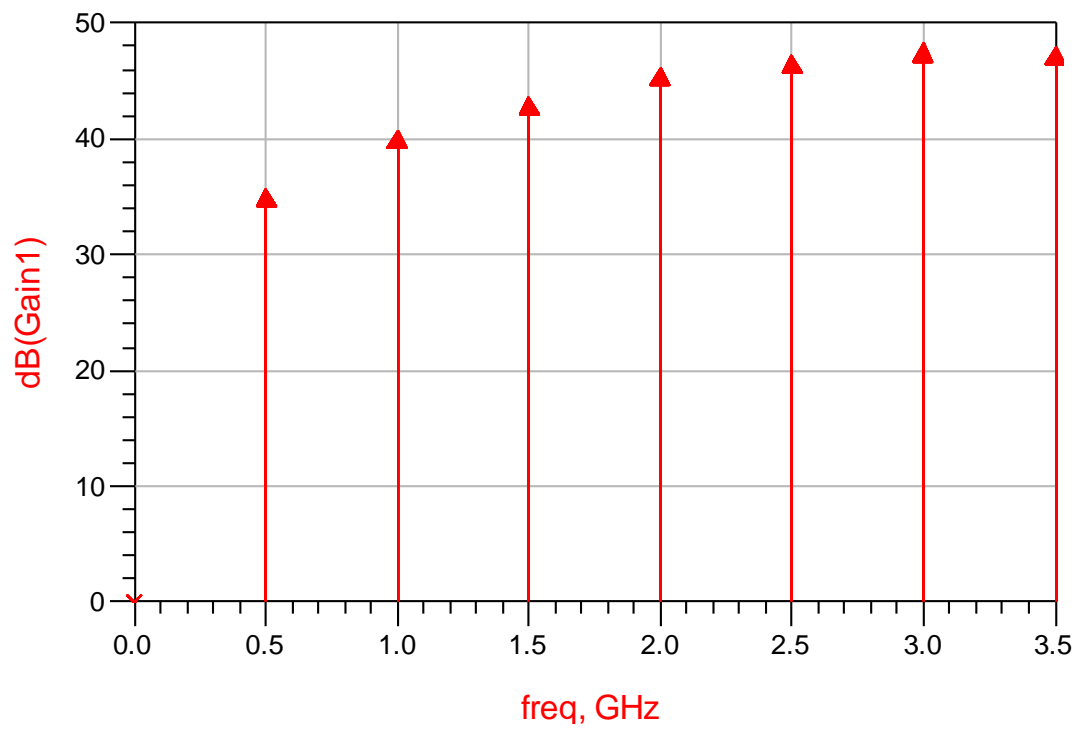

Figure 11. Gain diagram index. 


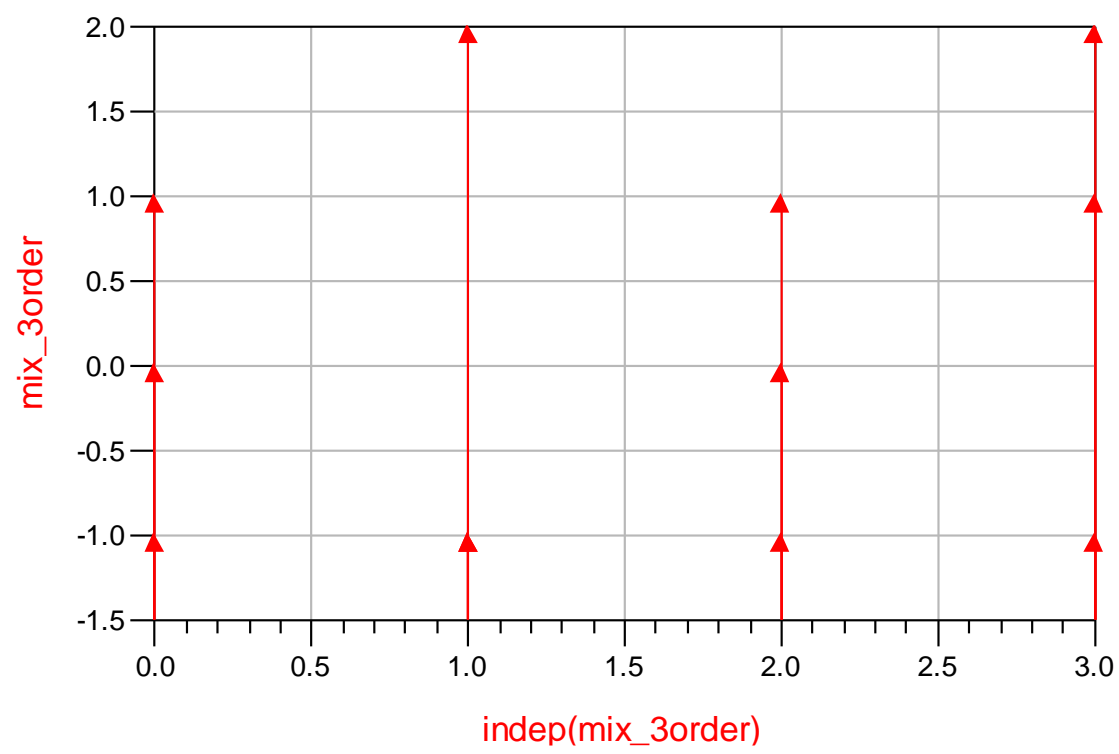

Figure 12. Harmonic Differential Third-order.

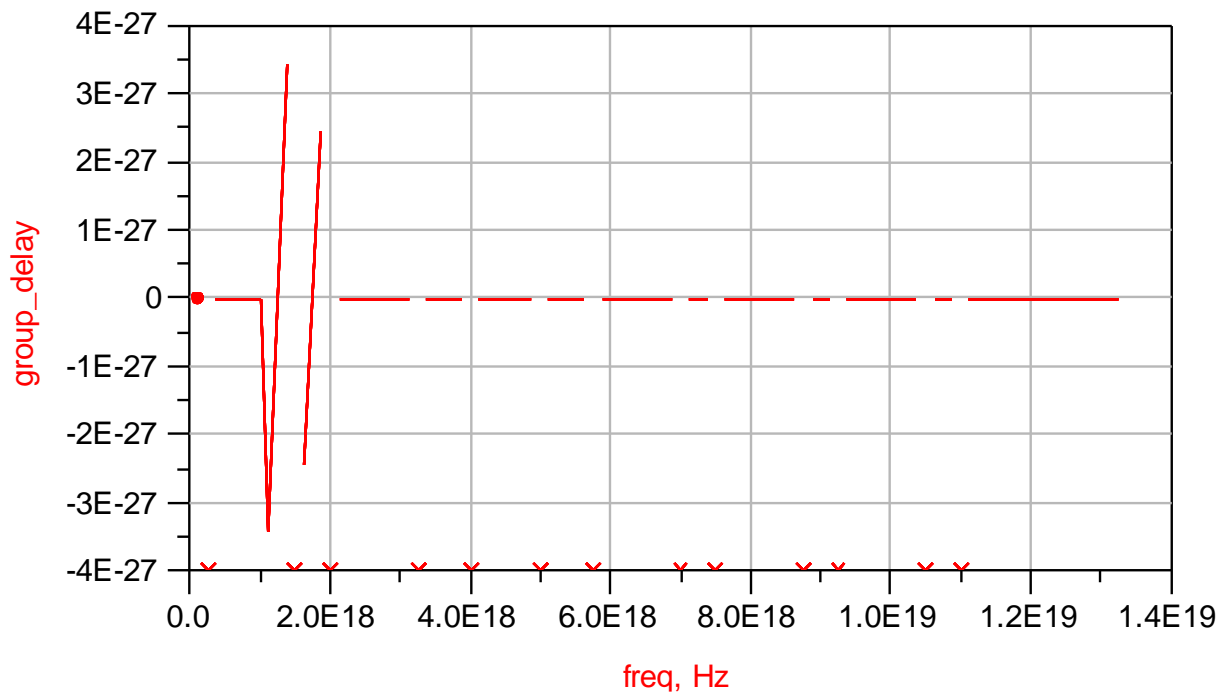

Figure 13. Characteristic of the harmonic phase harmonic frequency spectrum in terms of frequency.
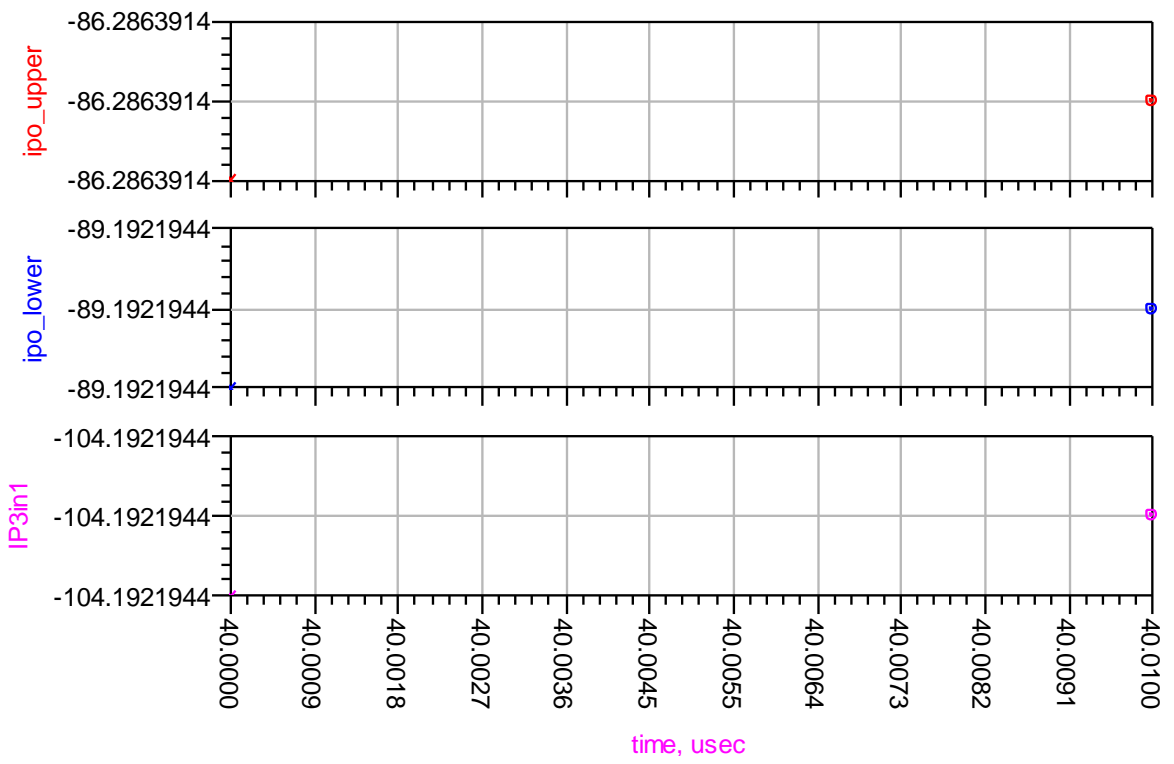

Figure 14. Chart and IP3 values. 
Table 2 shows that the present LNA has the highest FOM when compared against other L-band LNAs.

$$
F O M=\frac{S_{21}(m a g) . I I P 3(m W)}{[N F(m a g)-1] . P_{d i s s}(m W)}
$$

Table 2. Performance comparison between other l-band low noise amplifiers

\begin{tabular}{ccccccc}
\hline FOM & Technology & $\mathbf{N F}(\mathbf{d B})$ & $\mathbf{V C C}(\mathbf{V})$ & Gain $(\mathbf{d B})$ & Freq $(\mathbf{G H Z})$ & Reference \\
\hline 0.501 & $0.6 \mathrm{CMOS}$ & 2.8 & 1.5 & 21 & 1.5 & {$[1]$} \\
\hline 0.178 & $0.8 \mathrm{BiCMOS}$ & 2.7 & 2 & 10 & 1.9 & {$[2]$} \\
\hline 5.381 & HBT & 2 & 2 & 111.1 & 1.83 & {$[3]$} \\
\hline 4.631 & $0.25 \mathrm{CMOS}$ & 0.8 & 1.5 & 20 & 1.22 & {$[4]$} \\
\hline 4.497 & $0.25 \mathrm{CMOS}$ & 1.3 & 1.5 & 16.5 & 1.57 & {$[5]$} \\
\hline 7.4 & $0.18 \mathrm{CMOS}$ & 2.6 & 1.5 & 22.2 & 1.82 & This Work \\
\hline
\end{tabular}

\section{4- Conclusion}

In this paper, we have design and described the LNA circuit in the frequency band L. This circuit is designed with the 0.18 CMOS technology structure. The purpose of this design is to improve the quantity: Gain - Noise Figure Linearization - Reduced power consumption and circuit stability. This circuit is also used in various wireless systems, including GPS systems and short-range satellite radio frequencies. After designing the circuit, we analyzed the quantities that these quantities were analyzed based on equations or based on the boxes specified in ADS software.

\section{5- Acknowledgement}

Research Company APM very grateful that we were in this Reserch support. Mr. Taiyeb Namdaran and Mr. Hamed Moradi research director at the company, sincerely thank.

\section{6- References}

[1] John Chung Hang Poh, Peng Cheng, Tushar K. Thrivikraman, And John D. Cressler, "High Gain, High Linearity, L-Band Sige Low Noise Amplifier With Fully-Integrated Matching Network", 978-1-4244-5458-7/10/\$26.00 @ 2010, IEEE.

[2] Felix Gunawan, Basuki Rachmatul Alam, "Design And Modulation Analysis Of Cascade Lna For L-Band Very Low Magnitude Signal”, 978-1-5090-5170-0/16/\$31.00 @2016 IEEE.

[3] P. Leroux, J. Janssens, And M. Steyaert, “A 0.8-Db Nf Esd-Protected 9-Mw Cmos Lna Operating At 1.23 Ghz,” IEEE Journal Of Solid-State Circuits, Vol. 37, No. 6, Pp. 760-765, June 2015.

[4] J. -S. Rieh, D. Greenberg, M. Khater, K. T. Schonenberg, S. -J. Jeng, F. Pagette, T. Adam, A, Chinthakindi, J. Florkey, B. Jagannathan, J. Johnson, R. Krishnasamy, D. Sandeson, C, Schnabel, P. Smith, A. Striker, S. Sweeney, K. Vaed, T. Yanagisawa, D. Ahlgren, K. Stein, And G. Freeman, "Sige Hbts For Millimeter-Wave Application With Simultaneously Optimized Ft And Fmax Of 300 Ghz,” IEEE Radio Frequency Integrated Circuits Symposium, Pp. 395-398, June 2015.

[5] P. R. Gray, P. J. Hurst, S. H. Lewis, And R. G. Meyer, Analysis And Design Of Analog Integrated Circuits, 4th Edition, John Wiley \& Sons, 2011.

[6] W. -M. L. Kuo, Q. Liang, J. D. Cressler, And M. A. Mitchell, “An X-Band Sige Lna With 1.36 Db Mean Noise Figure For Monolithic Phased Array Transmit/Receive Radar Modules,” IEEE Radio Frequency Integrated Circuits Symposium, Pp. 501-505, June 2013.

[7] C. -W. Kim, M. -S. Kang, P. T. Anh, H. -T. Kim, And S. -G. Lee, “An Ultra-Wideband Cmos Low Noise Amplifier For 3-5 Ghz Uwb System,” IEEE Journal Of Solid-State Circuits, Vol. 40, No.2, Pp. 544-547, Feb 2015.

[8] H. Spieler, Semiconductor Detector Systems, Oxford University Press, 2016.

[9] W. M. Leach, "Fundamentals of Low-Noise Analog Circuit Design," Proceedings of The IEEE, Vol. 82, Issue 10, Pp. 1515-1538, Oct 2014.

[10] T. K. Thrivikraman, W. -M. L. Kuo, J. P. Comeau, A. K. Sutton, J. D. Cressler, P. W. Marshall, And M. A. Mitchell, “A 2 Mw, Sub-2 Db Noise Figure, Sige Low-Noise Amplifier For X-Band High-Altitude Or Space-Based Radar Applications," IEEE Radio Frequency Integrated Circuits Symposium, Pp. 629-632, June 2010. 
[11] D. K. Shaeffer and T. H. Lee, "A 1.5 V, 1.5 Ghz Cmos Low Noise Amplifier," IEEE Journal of Solid-State Circuits, Vol. 32, Issue. 5, Pp. 745-759, May 2009.

[12] N. Suematsu, M. Ono, S. Kubo, H. Sato, Y. Iyama And O. Ishida, "L-Band Internally Matched Si-Mmic Low Noise Amplifier," Ieee Mtt-S International Microwave Symposium Digest, Vol. 3, Pp. 1225-1228, June 2013.

[13] K.W. Kobayashi, A. K. Oki, L. T. Tran And D. C. Streit, “Ultra-Low Dc Power Gaas Hbt S-Band Low Noise Amplifiers,” IEEE Microwave And Millimeter-Wave Monolithic Circuits Symposium, Pp. 73-76, May 2012.

[14] P. Leroux, J. Janssens And M. Steyaert, “A 0.8-Db Nf Esd-Protected 9 Mw Cmos Lna Operating At 1.23 Ghz,” IEEE Journal of Solid-State Circuits, Vol. 37, No. 6, Pp. 760-765, June 2012.

[15] P. Lerous, M. Steyaert, V. Vassilev and G. Groeseneken, “A 1.3 Db Nf Cmos Lna For Gps With 3 Kv Hbm Esd-Protection,”

Proceedings of The 28th European Solid-State Circuits Conference, Pp. 335-338, Sept .213.

[16] U. Alvarado, N. Rodriguez, J. Mendizabal, R. Berenguer And G. Bistue, "A Dual-Gain Esd-Protected Lna With Integrated Antenna Sensor For A Combined Galileo And Gps Front-End," Topical Meeting On Silicon Monolithic Integrated Circuits In Rf Systems, Pp. 99-102, Jan. 2015. 